\title{
Standardization and Improvement of Village-level Accountant Principal-Agent System from the Perspective of Financial Management
}

\author{
Yun Sun ${ }^{1}$, Liulin Lin ${ }^{2}$, Xun Zhao ${ }^{1,3}$ \\ ${ }^{1}$ Beijing Normal University.Zhuhai, Zhuhai Guangdong, 519085, China \\ ${ }^{2}$ Zhuhai City Polytechnic, Zhuhai Guangdong, 519040, China \\ ${ }^{3}$ University of Macau, Zhuhai Guangdong, 519015, China
}

Key words: Perspective of financial management, Village-level accountant principal-agent system, Standardization and improvement measures.

\begin{abstract}
Extensive attention is paid to the application of village-level accountant principal-agent system from the perspective of financial management. Relevant management personnel must improve and standardize it according to actual work requirements of financial management, improve the feasibility of village-level accountant principal-agent system, optimize its development system and achieve the expected work purpose.
\end{abstract}

\section{Introduction}

Relevant departments should attach adequate importance to the improvement and standardization of village-level accountant principal-agent system, guarantee to improve their work quality in actual work, reduce various existing problems and optimize the implementation system of village-level accountant principal-agent system.

\section{Status of village-level financial management work}

Some problems difficult to solve still exist during actual development in some village-level financial management work, which influence the quality and reliability of financial management work and even reduce the work quality of accountant. They are specifically manifested as below:

First, it is difficult to implement work system. Some village-level financial departments cannot implement various financial management systems during actual work. During actual implementation of accountant principal-agent system, relevant departments cannot manage it comprehensively or solve problems of village-level financial accounting management work. It is difficult for them to improve their work quality, thus even influencing the economic benefit of villages. Meanwhile, during actual work of financial department, relevant personnel cannot conduct comprehensive analysis and management on the practical situation and bearing capacity of village-level collective economic income or improve the work quality of village-level financial department.

Second, lack a complete supervision system. Village-level financial accountant principal-agent system is not standardized from the perspective of financial management. Relevant department cannot improve its supervision system, discover existing problems in work in time or take effective measures to solve problems. It lacks supervision in advance, in-process monitoring and afterwards treatment. According to relevant investigation, many problems exist in village-level financial supervision department. First, the establishment of concealed accounts against rules. Some village-level financial management workers fail to realize the importance of funds management and financial management work and carry out management activities with advanced management mode in actual work. Second, ticket management. Some village-level financial departments cannot conduct 
comprehensive management over tickets or improve the work quality of village-level accountant principal-agent system. It is difficult for them to optimize its development system. Meanwhile, some village-level financial departments cannot reserve receipts better in actual work and even have the phenomenon of incomplete receipts. They cannot optimize their development system and it is difficult to improve the quality of village-level financial management work. Finally, original certificate management work. While managing original accounting documents, some accountants cannot guarantee their authenticity and reasonability, which will even influence the long-term progress of the whole administrative village.

Third, lack complete talent team. From the perspective of financial management, village-level financial management department fails to build a high-quality talent team, entrust accountants with high professional quality and certain work experience and build a high-quality accountant talent team in the process of applying accountant principal-agent system, which will even influence the overall quality of financial management work. On the one hand, the phenomenon of violation against rules often occurs in financial management work. It is difficult to carry out work according to relevant village-level rules and even problems difficult to solve occur. On the other hand, village-level financial department easily has asset management loophole during accountant principal-agent and it is difficult to improve the quality of financial management work.

Forth, lack correct management concept. Some village-level financial management departments fail to realize the importance of their work and establish correct management concept in actual work and development. In particular, as they do not regard accountant principal-agent system as a key content in the application process, they fail to realize the importance of agent work and establish a complete management system in actual work and development. It is difficult for them to improve the normalization and completeness of village-level accountant principal-agent system.

Fifth, lack complete basic work of accounting. From the perspective of financial management, village-level financial department fails to realize the importance of accountant principal-agent system and process it with advanced management mode in actual work. It is difficult to improve its work quality. Meanwhile, a complete management system is not established during the setting of accounting account and budget preparation. Its work quality and reliability cannot be improved. Even the normalization of accounting account will be influenced. The phenomenon of account manipulation occurs. The reliability of accountant principle-agent system cannot be improved.

Sixth, lack a complete disclosure system of finance. From the perspective of financial management, village-level department cannot establish a complete disclosure management system or improve the reliability of accountant principal-agent system. Even some problems that cannot be solved occur ${ }^{[1]}$.

\section{Working concept of village-level accountant principal-agent system from the perspective of financial management}

From the perspective of financial management, relevant departments must be clear about their work concept according to features and advantages of village-level accountant principal-agent system, process it comprehensively, improve the work quality of principal-agent system and lay a foundation for its subsequent development. Specific concepts include the following:

First, establish objective assessment system. During village-level financial management, relevant departments should establish a complete accounting work objective assessment system and improve their work reliability in order to apply accountant principal-agent system scientifically. First, relevant departments should reform financial management work, set up a correct work concept and build assessment management system based on actual development demands of village-level financial department. Second, relevant departments should implement financial examination and approval work, manage various assets and goods and improve their work quality. Finally, village-level financial department should analyze requirements for the application of accountant principal-agent system scientifically in actual work, carry out assessment work periodically, assess financial management work of principal-agent department monthly or annually, specify assessment work 
mode, implement relevant management work with advanced evaluation mode, gradually improve the feasibility and implementation efficiency of village-level accountant principal-agent system and reduce problems of village-level financial management work from the perspective of financial management. Meanwhile, it is also required to strengthen the implementation effect of financial management system with objective assessment mode, enhance the execution of financial management system and achieve the expected work purpose ${ }^{[2]}$.

Second, governments at three levels and institutions at six levels should make joint efforts to implement relevant work. From the perspective of financial management, the application of village-level accountant principal-agent system requires mutual cooperation of government sectors at three levels and institutions at six levels as relevant department has set up a management system composed of institutions at six levels in village-level financial management work. Workers must conduct comprehensive analysis on it, guarantee to connect each department and institutions, conduct effective management over them and reduce accounting work problems existing ${ }^{[3]}$.First, establish cashier business handling system. To apply accountant principal-agent system better in the process of village-level financial management, it is required to implement cashier business handling work scientifically, guarantee to improve its work quality, implement advanced receipt and payment and bank settlement services according to relevant laws and regulations and improve work quality. Meanwhile, it is required to cooperate with accounting service station and accept the guidance and supervision of relevant department so as to improve the quality of village-level financial accounting management work ${ }^{[4]}$.Second, establish a complete service station management scheme. Village-level financial management department should establish a complete service station management scheme, guarantee to establish complete management system for accounting service station, unify bill management mode, accounting work form, accounting data control and filing work management and improve work reliability of service station. Finally, establish a complete business guidance and supervision system of agricultural economic management station. Village-level financial management department should attach importance to business management of agricultural economic management station, arrange workers with high professional quality for supervision, discover problems existing in business work in time, bring forward opinions for solving problems and guarantee to improve its guidance and supervision work quality and optimize its development system. In addition, relevant department should guarantee the normalization and reliability of its work, improve the normalization of village-level accountant principal-agent system, optimize its development system, strengthen the implementation of relevant system and guarantee to meet requirements for modern village-level financial management work.

Third, promote the development of accounting computerization and management networking. In actual application of village-level accountant principal-agent system, workers should apply network information technology scientifically, give play to the application of modern information technology and improve the advancement of accounting work. First, village-level financial department should establish a professional accounting service station, improve it with network information technology and digital technology, improve its level of advancement and automation and optimize its working mode. Meanwhile, it is required to reform working mechanism, discover deficiencies of rural financial work in time, take effective measures to make up for deficiencies and achieve the required work purpose. Second, relevant department should build advanced infrastructure positively, introduce computer equipment and computerized equipment and gradually improve its service level in rural financial management work. Finally, relevant department should supervise funds management of village-level departments dynamically with permission setting and improve its management level in rural financial management work.

Forth, improve village-level financial management efficiency. Village-level financial management department should comprehensively analyze requirements from the perspective of financial management, connect standardized management and democratic financial management and improve its work efficiency. First, conduct standardized open management over time, guarantee the implementation of various kinds of work in time according to relevant provisions and improve its 
work accuracy. Second, standardize the disclosure of financial management contents, establish village-level financial data information disclosure system, make it transparent and improve the reliability of village-level financial management so as to improve the understanding and support of peasants. Finally, standardize disclosure form. Village-level financial department should improve its work convenience and practicability, standardize disclosure form, build a complete public bar and announce its work scale and financial rules comprehensively so that peasants can understand actual connotations of village-level financial accountant principal-agent system. Meanwhile, it is required to improve the stringency of financial work and optimize its work mechanism ${ }^{[5]}$.

\section{Measures for standardization and improvement of village-level accountant principal-agent system from the perspective of financial management}

From the perspective of financial management, relevant departments must improve and standardize village-level accountant principal-agent system, improve the level of village-level financial management work, optimize its development system and guarantee to improve the effect of modern village-level financial management work. Specific measures include the following:

\section{Strengthen the sense of responsibility of government sector}

Government at all levels must conduct comprehensive examination and audit according to village-level financial management work requirements, implement assessment work periodically and improve its work quality in actual work. First, government sector should conduct supervision on village-level accounting service station and relevant departments, conduct periodic examination and improve its work quality in actual examination work. Second, in terms of audit work, government sector should audit account data of village-level financial receipt and payment, cooperate with the Bureau of Land Management in management over land compensation funds and avoid village-level financial management problems. Financial items emphasized by the masses should be audited emphatically. Third, in terms of assessment work, relevant department should establish a complete assessment scheme, set up a special assessment team to be responsible for the assessment of village-level financial management and implement relevant work periodically. Forth, in terms of ranking, relevant department should discover existing problems in time through audit and examination according to the summary of assessment result, take effective measures to solve problems and gradually improve its work quality.

\section{Highlight the principal position of village-level department}

In village-level financial supervision and management, relevant competent departments such as agricultural economic management station should take many management responsibilities and have great amount of work. With its management over village-level finance alone, it is impossible to improve the application quality of accountant principal-agent system. Therefore, village-level financial management department should highlight its principal position, improve its work quality and efficiency and achieve the expected management purpose. First, village-level department should be clear about assessment responsibilities of leading cadres, implement work responsibilities and guarantee to attach importance to its supervision work in actual work. Meanwhile, work form should be specified. Second, relevant department should specify the work object of assessment and improve its work quality with objective assessment method. Finally, it is required to build a high-quality talent team, employ principal-agent accountants and require them to attach importance to their work responsibilities in actual work.

\section{Establish assessment and training guidance system}

In village-level accountant principal-agent system, relevant departments should conduct assessment work well, establish appropriate assessment scheme, be clear about the practical situation of village-level finance and conduct comprehensive assessment. In assessment work, it is required to innovate work mode and improve work quality. In terms of training guidance work, it is necessary to 
assess village-level cashiers so that they can take appointment with certificate, be clear about their work purpose, gradually improve their work quality and reduce existing problems. Finally, relevant workers should process the system effectively, reduce financial accounting work problems and improve its work mechanism in the standardization and improvement of village-level accountant principal-agent system.

\section{Conclusion}

From the perspective of financial management, the construction of village-level accountant principal-agent system requires relevant departments to improve and standardize it, improve their work quality, optimize its development system and achieve the expected management purpose.

\section{References}

[1] Peng Qiaojing. Game Analysis on Village-level Accountant Principal-agent System under the Background of New Rural Construction, Agricultural Economy, 2014(5):60-61.

[2] Sun Hongzhi. Existing Problems of Village-level Accountant Principal-agent System and Countermeasures, Assets and Finance of Administrative Undertaking, 2014(6):150.

[3] Mei Yufang. Promote Standardized Management of Village Collective Finance with Village-level Accountant Principal-agent System, Rural Economy and Technology, 2016(10):86-87.

[4] Li Long. Problems of Village-level Accountant Principal-agent System in Agricultural Economy and Countermeasures, Southern Agricultural Machinery, 2016,47(7):30,37.

[5] Zhang Zixiang. Investigation and Thinking on Implementation of Village-level Accountant Principal-agent System, Yunnan Agriculture, 2014(11):58-60. 